\title{
Merkezi Sınavlardaki Soru Kitapçıklarına A* Algoritması ile Derslerin Yerleştirilmesi
}

Sinan KUL, Atatürk Üniversitesi, Bilgisayar Kullanımı, Dr. Öğr. Üyesi, sinan.kul@atauni.edu.tr, 0000-0002-7824-756X

Mehmet Sinan BAŞAR, Atatürk Üniversitesi, İşletme, Doç. Dr., sinanb@atauni.edu.tr, 0000-0002-6741-6268

$\ddot{O Z Z}$

Bu çalışmanın amacı Açıö̈̆retim Fakülteleri için gerçekleştirilen sınavlarda kullanılan kitapçıklardaki ders tekrarların azaltarak, toplamda üretilen farklı kitapçık sayısını düşürmektir. Bu şekilde baskı maliyetlerini ve işlem karmaşıklığını azaltarak işlem süresini ve bu süreçteki olası hataların azaltılması hedeflenmektedir. Kitapçıklara dersler tanımlanırken, derslere ilişkin sınavların hangi oturumlarda yapılacă̆g bilgisi ile öğrenci ders alma bilgisi kullamılmaktadır. Diğer taraftan herhangi bir öğrencinin tüm derslerinin bir kitapçıkta bulunması ve bir kitapçıkta en fazla 15 ders bulunması kısıtlarma uyulmaktadır.

Kitapçıklara ders ataması probleminin çözümü için $A^{*}$ algoritması kullanılmıştır. İlk kitapçı̆̆a ilk ders ataması yapılırken öğrenci ders alma bilgisi kullanılmış ve en fazla öğrenci tarafindan alınan ders ilk kitapçı̆̆a yerleştirilmiştir. Kitapçıkta yer alacak diğer tüm derslerin seçiminde ise seçilecek dersle birlikte kitapçıktaki derslerden başka dersi kalmayan öğrenci sayısının maksimum olması hedeflenmiştir.

Çalışma öncesi durumda, üç oturumda gerçekleştirilen sınavlar için 1. oturumda 18, 2. Oturumda 18 ve 3. Oturumda 8 olmak üzere toplamda 44 adet farklı kitapçı bulunmaktadır. Çalı̧̧ma sonucunda ise toplamda 24 tür kitapçı üretilmiştir. Tekrar eden ders sayısı artmasına rağmen kitapçık sayısı nerdeyse yarı yarıya azaltılabilmiştir.

Anahtar : $\quad$ Merkezi Sınav, Açıköğretim, Sezgisel Algoritma, Soru Kitapçığı, Sınav Oturumu, A*

Kelimeler

\section{Placing the Courses in Question Booklets with A* Algorithm in Central Exams}

\begin{abstract}
The aim of this study is to optimize the question booklets used in exams conducted for Open Education Faculties.

For this purpose, it is aimed to prevent the repetition of courses in different booklets and to reduce the number of different booklets. In this way, it will be possible to reduce the total time and possible errors by reducing printing costs and processing complexity.
\end{abstract}


While determining which courses will be included in which booklet, the information on which sessions the exams will take place and the student course taking information are used. While determining the booklets, the following restrictions must be followed: All courses a student will take in a session must be included in same booklet and each booklet can contain a maximum of 15 courses.

$A{ }^{*}$ algorithm was used to solve the problem of assigning courses to the booklets.

While the first course assignment was made to the first booklet, the student course taking information was used and the courses taken by the students at most were placed in the first booklet. While choosing other courses to be included in the booklet, it is aimed to have a maximum number of students who do not have any other courses.

In the pre-study situation, there are 44 different booklets in total, 18 in the 1st session, 18 in the 2 nd session and 8 in the $3 r d$ session, for the exams held in three sessions. As a result of the study, a total of 24 types of booklets were produced. Despite the increase in the number of repeating courses, the number of booklets could be reduced by almost half.

Keywords : Central Exam, Open Education, Heuristic Algorithm, Question Booklet, Exam Session, $A^{*}$

\section{EXTENDED ABSTRACT}

Establishing the exam calendar and determining the exam sessions of the courses are among the most important problems in exam organizations. This process is called scheduling. The main purpose is to be fulfilled the performance criteria as much as possible while the exam sessions are determined within certain rules and constraints. Minimizing the total number of classrooms used during the exam period, spreading the exams evenly throughout the exam period, and being able to perform the exam smoothly and at low cost are some of these criteria. In addition to these, it is aimed to prevent negativities that may hinder the academic success of the students who will take the exam. For this, courses with high levels of difficulty should be assigned to as far away time zones as possible from each other. In addition, the criteria of minimizing the number of students taking the exam on the same day, preparing the exam program for each student in a balanced way, and assigning the exams to the appropriate time period according to the difficulty levels are also important.

When defining the organization of the exam, it is important to know whether the exam will be conducted in a specific unit or in more than one center. While large-scale central exams are planned, the planning, coordination and execution of the processes can be carried out from one center, and the application of the exam can be done in a limited time in many areas, buildings and classrooms. Since central exams are usually scheduled on weekends, they can take up to 4 sessions at most. Since students can take exams from more than one course in one session, there is no flexibility in determining different exam times for each course. In these 
exams, the student can distribute the total time to the lessons according to his / her own preference.

When planning central exams, many complex processes need to be handled together. Examples of these processes are the organization of the building and halls, the organization of the examiners, the printing, boxing and distribution of the exam documents to the exam units, and the return of the documents to the exam center at the end of the exam.

Within the centrally planned exams, the exams in which these processes are perhaps the most complex are those conducted at the faculties of open education. Because there are difficulties in open education faculties, such as planning for a large number of courses belonging to many programs and the list of courses for which each student will take the exam is different. Within the courses taught in the faculties of open education, there are many courses included in the curriculum of more than one department and called common courses. Since the learning outcomes, course content, book and exam questions of common courses are the same, students who take these courses must take the exam in the same session. This requirement complicates the planning of sessions for many programs and the creation of question booklets.

The high number of lectures in a booklet reduces the number of booklet types but increases printing costs. The model with the lowest printing cost is the creation of the same type of booklet only for students who take the same courses. In this case, since the number of booklet types will increase too much, the operations become very complicated. In addition, other costs such as time and labor are increasing and the risk of faulty operations increases. Considering all these limitations, it was evaluated that having 15 lessons in a booklet can minimize both printing costs and the number of booklet types.

When evaluated in terms of exam buildings and halls, there are the following restrictions on the determination of booklets: Having a single booklet type in a hall makes it easier for the hall attendants. Having one booklet type in a building reduces potential confusion and guarantees trouble-free testing with fewer spare booklets. In order to have the least number of booklet types to be allocated to the buildings, the number of students taking the exam from a booklet should be kept high.

The aim of this study is to reduce the number of different booklets produced in total by reducing the availability of a course in more than one booklet in exams held for Open Education Faculties. In this way, it is aimed to reduce the processing time and possible errors in this process by reducing printing costs and process complexity.

While defining which courses will take place in which booklet, the information on which sessions the exams will be held for the courses and the student course taking information are used. $A^{*}$ algorithm was used to solve the problem of assigning courses to the 
booklets. While the first course assignment was made to the first booklet, student course taking information was used. The courses taken by the most students are placed in the first booklet. While selecting other courses to be included in the booklet, it is aimed to have a maximum number of students who will not have any more courses to take the exam together with the course to be chosen. Currently, there are 44 different booklets in total for the exams held in three sessions, 18 in the 1st session, 18 in the 2nd session, and 8 in the 3 rd session. As a result of the study, a total of 24 types of booklets were produced. Despite the increase in the number of repeating courses, the number of booklets could be reduced by almost half.

\section{GİRIŞ}

Sınav organizasyonlarında en çok odaklanılan problem derslerin sınav oturumlarına yerleştirilmesi ve sınav takviminin oluşturulmasıdır. Çizelgeleme olarak adlandırılan bu işlemde temel amaç, sınav oturumları belirli kurallar ve kısıtlar dâhilinde belirlenirken performans kriterlerinin de mümkün olduğu kadar yerine getirilmesidir (Ceylan vd., 2019). Sınav takviminin oluşturulmasında performans kriterlerine şu şekilde örnek verilebilir:

- Zorluk derecesi yüksek olan derslerin birbirinden mümkün olduğu kadar uzak zaman dilimlerine atanması

- Sinavların, sınav dönemi boyunca dengeli olarak yayılması

- Aynı günde sınava giren öğrenci sayısının minimize edilmesi

- Her öğrenci için sınav programının dengeli hazırlanması

- Sınav döneminde kullanılan toplam derslik sayısının minimize edilmesi

- Sinavların zorluk derecelerine göre uygun zaman dilimine atanması

Sınavların organizasyonları çizelgelenirken sınavın gerçekleştirileceği akademik kurumun amaçları ve öncelikleri ile kısıtlayıcılar açısından farklı modellerin uygulanması söz konusu olabilir (Çoruhlu, 2007). Literatür incelendiğinde sınav organizasyonları ile ilgili birçok çalışmanın sınav takviminin hazırlanmasına odaklandığı görülmektedir. Bu bağlamda matematiksel programlama (Temur, 2006; Köçken vd., 2014; Matçı, 2014; Uçar vd., 2015; Altunay ve Tamer, 2016; Aslan vd., 2017 ), Hedef Programlama (Çoruhlu, 2007; Bergmann vd., 2014; Varlı vd., 2017), Stokastik Programlama (Sun vd., 2021), Genetik Algoritma (Kalaycl, 2008; Aksu, 2018; Seyfi, 2018; Ibrahim, Amin ve Saringat, 2020; Liu vd., 2020), GRA+ (Zhu ve Gningue, 2020, Yu, 2020), Benzersiz Kisitlar (Blanks vd., 2020) ve diğer sezgisel yöntemlerin (Ayob vd., 2011; Altıntaş, 2011; Acar ve Şevkli, 2013; Özçalıcı, 2017; Muklason vd., 2017) uygulandığı çok sayıda çalışma bulunmaktadır. Çalışmalarda karşılanması amaçlanan istek ve ihtiyaçlar doğrultusunda farklı amaçlar icra edilmiştir. Örneğin Kalaycı (2008) ve Leite ve diğerleri (2018) çalışmalarında, zor derslerin sınav takviminde aralarının açılmasını amaçlarken; Ayob vd. (2011) bir öğrencinin bir günde girdiği sınav sayısını minimize etmeyi; Altıntaş (2011) ve Seyfi (2018) ise bir öğrencinin girdiği sınavların arasını açmayı amaçlamıştır. 


\section{MERKEZİ SINAVLARDA KITAPÇIK OLUŞTURMA PROBLEMİ}

Sınav organizasyonu tanımlarken, sınavın belirli bir birimde mi yoksa birden çok merkezde mi yapılacağının planlandığının bilinmesi önemlidir. Merkezi sınavlarda süreçlerin planlanması, koordinasyonu ve yürütülmesi işlemleri bir merkezden yürütülürken; sınavın uygulanması, kısıtlı sürede, çok sayıda bölgede, binada ve sınıfta yapılabilmektedir. Merkezi olmayan sınavda ise sınav oturumları daha geniş bir zamana yayılmıştır ve her ders için farklı sürelere sahip ayrı bir oturum planlanabilmektedir. Genellikle hafta sonları yapılması planlandığı için en fazla 4 oturum olarak yapılabilen merkezi sınavlarda ise bir oturumda birden fazla dersten sinava girilebildiğinden her ders için farklı sınav süresi belirleme konusunda da esneklik bulunmamaktadır. Bu sınavlarda öğrenci toplam süreyi derslere kendi tercihine göre dağıtabilmektedir.

Merkezi sınavlar planlanırken de sinav oturumlarının belirlenmesi ve derslerin oturumlara dağıtılmasının yanı sıra kitapçıkların oluşturulması, bina ve salonların organizasyonu, sınav görevlilerinin organizasyonu, sınav evrakının basımı, kutulanması ve sınav birimlerine dağıtılması, sınav sonunda evrakların sınav merkezine geri taşınması gibi birçok karmaşık sürecin birlikte ele alınması gerekmektedir. Merkezi olarak planlanan ancak birden çok merkezde uygulanan sınavlar içerisinde bu süreçlerin belki de en karmaşık olduğu sınavlar açıköğretim yapan fakültelerde gerçekleştirilen merkezi sınavlardır. Diğer merkezi sınavlara ek olarak, açıköğretimde çok sayıda programa ait çok sayıda ders için planlama yapılması ve her öğrencinin sınava gireceği derslerin listesinin farklı olması karşılaşılan önemli zorluklardandır.

Açıöğretim yapan fakültelerde okutulan derslerin çoğu birden fazla bölüm altında okutulmaktadır. Ortak ders olarak adlandırılan bu derslerin öğrenme çıtıları, ders içeriği, kitabı ve sınav soruları ise aynı olduğu için sınav oturumlarının da aynı anda yapılması gerekliliği bulunmaktadır. Bu durum ise çok sayıda programa ait oturumların birlikte planlanmasını ve soru kitapçıklarının oluşturulmasını karmaşık hale getirmektedir.

Bir kitapçıkta bulunan ders sayısının fazla olması kitapçık tür sayısını azaltırken baskı maliyetlerini ise artırmaktadır. Baskı maliyetinin en az olduğu model ise sadece aynı dersleri alan öğrenciler için aynı tür kitapçığın oluşturulmasıdır ki bu durumda da kitapçık tür sayısı çok artacağından işlem karmaşası artmaktadır. Diğer taraftan zaman ve iş gücü gibi diğer maliyetlerin artmasina, hem de hatalara sebep olabilmektedir.

Farklı sayıda dersten sınava giren öğrencilere ortak kitapçıklar verildiğinde ise bu kitapçıklarda uygun sayıda ders bulunmadığı takdirde kitapçığın son sayfaları boş kalabilmektedir. Bütün bu kısıtlamalar dikkate alındığında bir kitapçıkta 15 ders bulunması, baskı maliyetlerini azaltırken kitapçı tür sayısını da minimize yapacağı değerlendirilmiştir.

Bina ve salon boyutuyla kitapçıklar değerlendirildiğinde ise bir salonda tek kitapçık türünün bulunması salon görevlilerinin işini kolaylaştırırken; bir binada tek kitapçık türünün 
bulunması, hem olası karışıklıkları azaltmakta hem de daha az sayıda yedek kitapçık ile sınavın sorunsuz yapılmasını garanti etmektedir. Binalara tahsis edilecek kitapçıların en az türde olabilmesi için de bir kitapçıktan sınava giren öğrenci sayısının yüksek tutulması ve kitapçık tür sayısının azaltılması gerekmektedir.

\section{MATERYAL VE YÖNTEM}

En uygun yol problemi için arama algoritmaları, belirli bir "başlangıç" dügüumünden "hedef" düğüme bir yol bulmak için kullanılmaktadır. Bu yol için olası tüm dügüumler arama alanını oluşturmaktadır. Arama algoritması da arama alanını tarayıp hedef dügüume ulaştıran yolu bulmaya çalışmaktadır. Arama algoritmalarını genel olarak iki grupta toplamak mümkündür:

- Uninformed Search (Bilmeden arama)

- Informed Search (Bilerek arama).

Arama işleminin bilmeyerek yapılması, arama algoritmasının, probleme özgü kolaylıkları barındırmaması anlamına gelir ki bu algoritmalarda, her durumda aynı şekilde çalışan ilkel yöntemler kullanılmaktadır. Arama işleminin bilerek yapılması durumunda ise algoritmanın probleme ait bazı özellikleri bünyesinde barındırması gerekir.

Bilmeden arama yöntemlerine nispeten daha verimli olan bilerek arama yapan algoritmalar, probleme göre değişiklik göstermektedir. Bilerek arama algoritmalarına örnek olarak en iyi ilk arama (BFS- Best First Search) verilebilir. Açgözlü arama algoritması ve A* algoritması da bu tür arama algoritmalarındandır.

1968 yılında Stanford Araştırma Enstitüsü tarafından geliştirilen A * algoritması, gerçek zamanlı olarak bilinen en iyi ilk kısa yol bulma algoritmasıdır. Best First Search (BFS) - “En İyi En Önce Arama” sınıfına giren A* algoritması hedefe ulaşmada hem gerçek uzunluk bilgisinin hem de sezgisel bilgilerin kullanılmasını içermesiyle Açgözlü Algoritma ve Dijkstra Algoritması'nın özelliklerini birlikte barındırmakta, gerçek maliyet ve sezgisel maliyet değerleri toplamı küçük olan dügüum üzerinden çözüme gitmektedir.

$A^{*}$ algoritmasında sezgisel fonksiyonun katkısı düşük olduğunda, en kısa yolu bulma işi yavaşlamaktadır. Sezgisel fonksiyon katkısı çok yüksek olursa da $A^{*}$ çok hızlı olmaktadır ancak en kısa yolu hesaplamak güçleşmektedir. Algoritmanın hızı ve doğruluğu arasındaki denge ise sezgisel tahminin doğruluğuna bağlıdır.

Aşağıdaki formülde $\mathrm{G}(\mathrm{x})$ başlangıç düğümünden ilgili düğüme kadarki gerçek maliyet iken; $H(x)$, ilgili düğümden hedef düğüme sezgisel (heuristic) maliyettir.

$$
F(x)=G(x)+H(x)
$$


Hedef düğümün mevcut $x$ dügüumünden ne kadar uzak olduğu konusundaki tahmin niteliğindeki $\mathrm{H}(\mathrm{x})$ kabul edilebilir aralıkta olmalıdır. $\mathrm{H}(\mathrm{x}), \mathrm{F}(\mathrm{x})^{\prime}$ in bir parçası olduğundan, $\mathrm{F}$ (x), en düşük yol maliyeti için $\mathrm{H}(\mathrm{x})$ 'e bağlıdır. $\mathrm{H}(\mathrm{x})$ kabul edilebilir olduğunda, $\mathrm{A}^{*}$ algoritmasının varsa en kısa yolu vereceği garanti edilir.

Arama sırasında her bir düğüm için ebeveyn düğüm ve düğüm durumu ("Ziyaret Edilmemiş", "Açık" veya "Kapalı") kaydedilir. "Ziyaret Edilmemiş" olarak işaretli bir düğüme gelindiğinde, dügümün durumu "açık" olarak değiştirilir. Açık bir düğümün tüm komşu düğümleri ziyaret edildiğinde ise bu düğümün durumu "kapalı" olarak işaretlenir ve ebeveyn dügüme dönülerek diğer seçenekler araştırılır.

$\mathrm{A}^{*}$ algoritması üzerine literatürde pek fazla çalışma bulunmamaktadır. Ziegler ve diğerleri (2008) yapılandırılmamış bir ortamda gezinmek için A* ile yol planlama yapmıştır. Inam (2009) ise $A^{*}$ algoritmasının farklı sayıda işlemci çekirdekleri için performansını analiz etmiştir.

Merkezi sınavlarda sınav kitapçıklarındaki derslerin belirlenmesi problemi konusunda da literatürde kısıtlı sayıda çalışmaya rastlanmıştır. Aygün ve Akçay (2015) tarafından yapılan çalışma tek modda, mesafeleri belli olan iller arasında A ilinden B iline gidebilmek için $A^{*}$ algoritmasının farklı sayıda işlemci çekirdekleriyle performansını analiz etmiştir. Inam (2009) tarafından yapılan çalışma ise $A^{*}$ algoritmasının hız problemine çözüm olması için paralel programlama (Cuda mimarisiyle) yaklaşımına odaklanmıştır. Bulut ve İnce (2017) ise çalışmalarında, tam sayılı programlama yöntemine sezgisel ve açgözlü bir yaklaşım ekleyerek "sırt çantası" problemine uygulayarak hesaplama zamanını düşürebilmişlerdir.

Sınav kitapçıklarındaki derslerin belirlenmesi problemi mevcut durumda karınca kolonisi algoritması kullanılarak çözülmektedir. Zaman ve maliyet etkinliği ile öğrenci memnuniyetinin arttırılması ihtiyacı ve bu ihtiyaçlardan kaynaklanan yeni kısıtlar, sürecin iyileştirilmesi için motive edici faktörler olmuştur. Bu faktörler açısından uygulanacak yeni yöntemin amaçları şu şekilde belirlenmiştir:

- İşlem sayısının ve toplam işlem zamanının azaltılması,

- Sinav uygulama maliyetlerinin düşürülmesi,

- Baskı ve kutulama işlemlerinde zamandan tasarruf edilmesi ve hataların azaltılmas1

- Aynı salonda ve aynı binada mümkün olduğunca az türden kitapçı kullanılması

- Öğrencilerin sınav oturumları ile ilgili taleplerinin mümkün olduğu kadar karşılanması sağlanarak toplam akademik başarının ve öğrenci memnuniyetinin arttırılması.

- Kitapçılarda boş bırakılan sayfaların sayısının azaltılması 
$\mathrm{Bu}$ amaçlar gerçekleştirilirken uyulması gereken kısıtlayıcılar ise şu şekilde stralanabilir:

- Bir kitapçıkta bir öğrenciye ait en fazla beş ders bulunabilir.

- Her bir ders için 20 soru sorulmalı ve soru kitapçığında iki sayfaya sığacak şekilde ayarlanmalıdır.

- Baskı teknikleri açısından kitapçıklar 2 kapak sayfasıyla birlikte 16 (7 ders) ya da 32 (15 ders) sayfadan oluşabilir.

- 16 sayfadan oluşan bir kitapçıta en fazla yedi, 32 sayfadan oluşan bir kitapçıta en fazla on beş derse ait sorular yer alabilir.

- Bir ders, birden fazla kitapçıta yer alabilir ancak farklı oturumlara ait kitapçıklarda yer alamaz.

- Her bir dersin hangi oturumda yer alacağı bilgisi önceden yapılan yerleştirmeye göre belirlenmiştir. Kitapçıklar oluşturulurken oturum sayısı (3) ve ders-oturum düzeni üzerinde değişiklik yapılamaz.

$\mathrm{Bu}$ çalışmada, derslere ait sınav sorularının hangi kitapçıklarda bulunacağı, oturumlardaki ders bilgisi ve öğrenci ders almaları bilgisi üzerinden $A^{*}$ algoritması kullanılarak belirlenmeye çalışılmıştır. Çalışmada diğer sezgisel algoritmalar değil de $A^{*}$ algoritmasının kullanılmasının sebebi, bu algoritmada hem gerçek hem sezgisel maliyetlerin birlikte dikkate alınabilmesiyle $\mathrm{A}^{*}$ algoritmasını araştırma problemimize uygun olmasıdır.

Kitapçıklara dersler atanırken de eklemeli yöntem uygulanmaktadır. Yani algoritmanın her bir iterasyonunda bir kitapçığa bir ders eklenmektedir. Algoritmaya göre kitapçığa ders eklenirken bu ders ile birlikte kitapçı̆̆ın maksimum sayıda öğrenciyi kapsaması amaçlanmaktadır. Böylece en az sayıda kitapçık türünün oluşturulabileceği değerlendirilmektedir.

\section{UYGULAMA}

Çalışma, Atatürk Üniversitesi Açıöŏgretim Fakültesi (ATA-AOF) bünyesinde yapılan merkezi sınavlar için uygulanmıştır. Yapılan uygulamanın amacı, kitapçılardaki ders tekrarlarını azaltarak, toplamda üretilen farklı kitapçık sayısını düşürmektir. Ulaşılan çözümün baskı maliyetleri, işlem karmaşıklığı, işlem süresi ve bu süreçteki olası hata oranı üzerindeki etkisi değerlendirilmiştir. Kitapçıklara dersler tanımlanırken, derslerin sınavlarının hangi oturumlarda olduğu bilgisi ve öğrenci ders alma bilgisi kullanılmaktadır.

ATA-AOF bünyesinde, 83 sinav merkezinde, 150 - 200 bin öğrencinin katıldığ sınav organizasyonları gerçekleştirilmektedir. Bu sınavlar uygulanırken sınavla doğrudan ilgili süreçlerin yanında yardımcı faaliyetlerin de eş zamanlı olarak yürütülmesi gerekmektedir. Sınav organizasyonundaki ana faaliyetler, sinav oturumlarının belirlenmesi, derslerin 
oturumlara dağıtılması, sınav binalarının ve salonlarının organizasyonu, kitapçıkların düzenlenmesi, sınav görevlilerinin organizasyonu olarak sayılabilir. Sınav merkezinde, ana faaliyetler dışında soruların hazırlanması, ders materyallerinin hazırlanması, basım, taşıma, sınav değerlendirme, itirazların değerlendirilmesi gibi birçok yardımcı faaliyet de yürütülmektedir.

Sinavlar hafta sonunda ve dört oturum (Cumartesi sabah, Cumartesi öğleden sonra, Pazar sabah ve Pazar öğleden sonra) olarak yapılabilmektedir. Ancak diğer organizasyonlar tarafından yapılan merkezi sınavlar dolayısıyla çakışma yaşanmaması için Fakülte yönetimi tarafından sınavların tamamının 3 oturumda yapılması yönünde karar alınmıştır. Diğer taraftan her bir ders için $30 \mathrm{dk}$ tahsis edildiğinden yine fakülte yönetimi tarafından bir öğrencinin bir oturumda beşten fazla dersten sınava girmesinin uygun olmayacağ 1 değerlendirilerek, karara bağlanmıştır.

Baskıda kullanılan standart kağıt boyutu A4 boyutunda bir kitapçı̆̆ın 16 yaprak ve 32 sayfa olmasını gerektirmektedir. Kitapçıklarda bir derse ait sorular iki sayfaya yerleşecek şekilde ayarlanmaktadır. Bu durumda ön ve arka kapaklar hariç 30 sayfaya soru yerleştirilmekte, bu durumda bir kitapçıkta en fazla 15 derse ait soru yet alabilmektedir. 16 sayfalık kitapçıklar için standart kağıdın önce ikiye bölünmesi daha sonra baskı makinesine konulması gerekmektedir. Bu durum ek işlemler gerektirmesine rağmen çalışma kapsamında yapılan uygulama, 32 sayfadan (15 ders) ve 16 sayfadan (7 ders) oluşan kitapçılar için ayrı ayrı yapılmış ve mevcut durumda kullanılan algoritma, elde edilen iki çözümle ile birlikte karşılaştırılmıştır.

\section{BULGULAR}

$\mathrm{A}^{*}$ algoritması kullanılarak hazırlanan yazılım ATA-AOF tarafından gerçekleştirilen son yüz yüze sınava ait bilgiler için uygulanmıştır. Söz konusu sınav 190113 öğrencinin katılımıyla ve üç oturumda toplam 181 ders için gerçekleştirilmiştir. Bir dersin birden fazla kitapçıkta yer alabilmesi sebebiyle tekrarlanan değerlerle birlikte kitapçıklarda yer alan ders sayısı 328 olarak belirlenmiştir. Öğrencilerin birden fazla oturumda sınava girebilmeleri sebebiyle tekrarlanan değerlerle birlikte sınava giren öğrenci sayısı ise 497768 olmuştur. Bu sayı hesaplanırken kullanılan cevap kâğıdı (optik form) sayısından yararlanılmıştır. Optik form sayısı ayrıca yedek kitapçıklar hariç basılan kitapçık sayısını da vermektedir. Kullanılan kitapçık türü sayısı 44 olmuştur. Her ders için kaç tür kitapçıta yer aldığı bilgisi Tablo 1'de görüldüğü gibidir. 
Tablo 1: Derslerin Yer Aldığı Kitapçık Türü Sayısı

\begin{tabular}{|c|c|}
\hline Ders Sayısı & Yer Aldı̆gı Kitapçık Türü Sayısı \\
\hline 130 & 1 \\
\hline 23 & 2 \\
\hline 9 & 3 \\
\hline 4 & 4 \\
\hline 2 & 5 \\
\hline 3 & 6 \\
\hline 3 & 7 \\
\hline 4 & 8 \\
\hline 2 & 9 \\
\hline 1 & 10 \\
\hline
\end{tabular}

Kitapçık türleri kitapçıkta yer alan ders sayısına göre sınıflandırıldığında ortaya çıkan sonuçlar Tablo 2' de görülebilir.

Tablo 2: Kitapçıklardaki Ders ve Basılan Kitapçık Sayıları

\begin{tabular}{|c|c|c|}
\hline Kitapçık Tür Sayısı & Kitapçıktaki Ders Sayısı & Basılan Kitapçık Sayısı \\
\hline 1 & 3 & 25 \\
\hline 4 & 4 & 3382 \\
\hline 12 & 5 & 149879 \\
\hline 1 & 6 & 2398 \\
\hline 9 & 7 & 161663 \\
\hline 2 & 8 & 1990 \\
\hline 7 & 9 & 34434 \\
\hline 3 & 10 & 11037 \\
\hline 1 & 12 & 7815 \\
\hline 1 & 14 & 57100 \\
\hline 3 & 15 & 68046 \\
\hline
\end{tabular}

Aynı sınava ait veriler $A^{*}$ algoritması ile hesaplandığında aşağıdaki sonuçlar elde edilmiştir:

1. Algoritma kullanılarak geçerli bir çözüme ulaşılmıştır.

2. Çözüm sonucunda tüm dersler kitapçıklara yerleştirilmiştir.

3. 32 sayfa ( 15 ders) için kullanılan kitapçık tür sayısı 24 olmuştur.

4. 16 sayfa (7 ders) için kullanılan kitapçı tür sayısı 81 olmuştur.

5. 32 sayfa (15 ders) için tekrarlanan değerlerle birlikte kitapçıklarda yer alan ders sayısı 343 olmuştur. 
6. 32 sayfa (15 ders) için tekrarlanan değerlerle birlikte sınava giren öğrenci sayısı 479784 olmuştur.

7. 16 sayfa (7 ders) için tekrarlanan değerlerle birlikte kitapçıklarda yer alan ders sayısı 561 olmuştur.

8. 16 sayfa (7 ders) için tekrarlanan değerlerle birlikte sınava giren öğrenci sayısı 475760 olmuştur.

9. Derslerin kaç tür kitapçıkta yer aldığı bilgisi Tablo 3 ve Tablo 4.te görüldügü gibidir.

Tablo 3: On Beş Dersten Oluşan Kitapçıklar için Derslerin Yer Aldığı Kitapçık Türü Sayısı

\begin{tabular}{|c|c|}
\hline Ders Sayısı & Yer Aldı̆̆ Kitapçık Türü Sayısı \\
\hline 99 & 1 \\
\hline 53 & 2 \\
\hline 13 & 3 \\
\hline 14 & 4 \\
\hline 3 & 5 \\
\hline 2 & 6 \\
\hline 2 & 8 \\
\hline
\end{tabular}

Tablo 4: Yedi Dersten Oluşan Kitapçıklar için Derslerin Yer Aldığı Kitapçık Türü Sayı

\begin{tabular}{|c|c|}
\hline Ders Sayısı & Yer Aldı̆̆ Kitapçık Türü Sayısı \\
\hline 75 & 1 \\
\hline 49 & 2 \\
\hline 20 & 3 \\
\hline 10 & 4 \\
\hline 10 & 5 \\
\hline 6 & 6 \\
\hline 4 & 7 \\
\hline 3 & 8 \\
\hline 2 & 9 \\
\hline 1 & 10 \\
\hline 1 & 11 \\
\hline 1 & 14 \\
\hline 2 & 15 \\
\hline 1 & 16 \\
\hline 1 & 24 \\
\hline 1 & 27 \\
\hline
\end{tabular}

10. Kitapçıkta yer alan ders sayısına göre kitapçık türleri Tablo 5 ve Tablo 6'da görüldüğü gibidir.

Tablo 5: On Beş Dersten Oluşan Kitapçıklar İçin Ders ve Basılan Kitapçık Sayıları 


\begin{tabular}{|c|c|c|}
\hline Kitapçık Tür Sayısı & Kitapçıktaki Ders Sayısı & Basılan Kitapçık Sayısı \\
\hline 1 & 5 & 304 \\
\hline 1 & 8 & 310 \\
\hline 22 & 15 & 479170 \\
\hline
\end{tabular}

Tablo 6: Yedi Dersten Oluşan Kitapçıklar İçin Ders ve Basılan Kitapçık Sayıları

\begin{tabular}{|c|c|c|}
\hline Kitapçık Tür Sayısı & Kitapçıktaki Ders Sayısı & Basılan Kitapçık Sayısı \\
\hline 1 & 3 & 1 \\
\hline 1 & 5 & 160 \\
\hline 79 & 7 & 475599 \\
\hline
\end{tabular}

\section{TARTIŞMA VE SONUÇ}

ATA-AOF sınavları için kullanılan metodun sonuçları ile karşılaştıııldığında $A^{*}$ algoritması kullanılarak elde edilen çözümün kitapçık türü sayısı, basılacak toplam kitapçık ve optik form sayısı, kullanılan zaman ve işgücü, işlemlerin kolaylaştırılması ve insan hatasından kaynaklanabilecek aksaklılar konusunda iyileştirme sağlayacağı sonucuna varılmıştır. Baskı maliyetleri konusunda $A^{*}$ ile yapılan dağıtımda 7 dersten oluşan kitapçıklar için daha düşük, 15 dersten oluşan kitapçıklar için daha yüksek maliyetlerle karşılaşılmış ancak bu artışın diğer maliyetlerde sağlanması beklenen azalışla telafi edilebileceği öngörülmüştür. Yani her iki durumda da toplam sınav uygulama maliyetleri azalmaktadır. Maliyet konusunda belirtilmesi gereken önemli bir husus mevcut uygulama ile elde edilen maliyet değerlerinin gerçek durumu yansıtmasına karşılık $A^{*}$ algoritması ile ortaya çıkacak maliyet değerlerinin tahmini olduğudur.

Kitapçıkların 32 sayfa olması, her kitapçığa en çok 15 derse ait soruların yerleştirilmesi kısıtına göre yapılan çözümde aşağıdaki konularda doğrudan ya da dolaylı olarak farklılık sağlayacak sonuçlar elde edilmiştir:

Kitapçık, form, bina ve salon sayıları: Uygulama sonucunda 44 olan kitapçı türü sayısı 24'e düşürülmüştür. Toplamda 497768 olan optik form sayısı 479784'e düşmektedir. Salonlarda sınava giren ortalama öğrenci sayısı temel alındığında sınavda kullanılacak salon sayısı 24900'den 24000'e düşmektedir. Bu da kullanılan bina sayısında yaklaşık olarak 60 kadar azalma anlamına gelmektedir. Kullanılan yedek kitapçık sayısı ise her bina için o binada kullanılan kitapçık türlerinin her birinden belirli sayıda yedek kitapçık gönderilmesi gerektiğinden, kitapçık türü sayısının azalması yedek soru kitapçıklarının sayısında da önemli bir düşüşe neden olacaktır. 
Sınav hazırlama süreçlerindeki değişiklikler: Kitapçık tür sayısının azalması bir sınıfta ya da bir binada tek tür kitapçık kullanılma ihtimalini önemli ölçüde arttıracak tek kitapçık türü kullanmanın mümkün olmadığı durumlarda kitapçık türü sayısını minimize edecektir. Bunun sonucunda bina ve salon evraklarının hazırlanması, poşetlenmesi, kutulanması gibi hazırlık süreçlerinde zaman ve işgücü açısından önemli avantaj sağlanabilecektir.

Baskı maliyetleri ve sınav uygulama maliyetleri: Elde edilen kitapçık dağılımının baskı maliyetlerini \%30 arttığ belirlenmiştir. Bu artış toplam sınav maliyetleri içerisinde \%1,5'a karşılık gelmektedir. Ancak bu durumda daha az bina ve salon kullanılacağından, yalnız sınav görevlilerine ödenen ücretlerden elde edilen tasarrufun toplam maliyet içerisindeki oranı $\% 1,7$ 'dir. Yani toplamda en az \%0,2 tasarruf sağlanabilmektedir.

İkinci çözümde ise kitapçıkların 16 sayfa olması, her kitapçı̆̆a en çok 7 dersin atanması kısıtı uygulanmış ve aşağıdaki sonuçlar elde edilmiştir:

Kitapçık, form, bina ve salon sayıları: Ugulama sonucunda 44 olan kitapçık türü sayısı 81'e çıkmıştır. Kullanılan optik form sayısı, 497768' dan 475760'a düşmektedir. Kullanılan bina ve salon sayısı ise salonlarda sınava giren ortalama öğrenci sayısı temel alındığında, 24900'den 23800'e düşmektedir. Bu da kullanılan bina sayısında yaklaşık olarak 73 kadar azalma anlamina gelmektedir.

Kullanılan yedek kitapçı sayısı: Kullanılan kitapçı türü sayısının artması yedek soru kitapçıklarının sayısında da artışa neden olacaktır. Bu durumun sınav maliyetlerine etkisi az olmasına karşılık iş süreçlerinin olumsuz etkilenmesine neden olacağı açıtır.

Sınav hazırlama süreçlerindeki değişiklikler: Kitapçık tür sayısının artması bir sınıfta ya da bir binada tek tür kitapçık kullanılma ihtimalini azaltacaktır. Bunun sonucunda bina ve salon evraklarının hazırlanması, poşetlenmesi, kutulanması gibi hazırlık süreçlerinde zaman ve işgücü açısından olumsuz etkiler ortaya çıkabilir.

Baskı maliyetleri ve sınav uygulama maliyetleri: Elde edilen kitapçık dağılımında baskı maliyetlerinin \%30 azaldığı belirlenmiştir. Bu yüzde, toplam sınav maliyetleri içerisinde \%1,5'a karşılık gelmektedir. Baskı maliyetlerinin azalması ile birlikte 15 ders kısıtına göre elde edilen çözümden de daha az bina ve salon kullanılacağından, yalnız sınav görevlilerine ödenen ücretlerden elde edilen tasarrufun toplam maliyet içerisindeki oranı \%1,8'dir. Yani toplamda en az \%3,3 tasarruf sağlanabilmektedir.

Sonuç olarak, A* algoritması ile elde edilen iki sonuç, mevcut uygulama sonuçları ile karşılaştırıldığında önemli iyileştirmeler sağladığ görülmektedir. Birinci çözümde kitapçık türü sayısı neredeyse yarıya düşürülmekte, maliyetler açısından kayda değer iyileştirme olmasa da süreçlerin iyileştirilmesi konusunda önemli fayda sağlanmaktadır. İkinci çözüm ise \%3'ten fazla maliyet azalması sağlamış ancak mevcut durumdan daha fazla iş gücüne ihtiyaç duyulacağı öngörülmüştür. Bu durumda iki alternatifli bir çözüm ortaya konmakta ve 


\section{AJIT-e Bilişim Teknolojileri Online Dergisi \\ Academic Journal of Information Tecnology}

2021 Spring/Bahar - Cilt/Vol: 12 - Sayı/Issue: 45

doi) 10.5824/ajite.2021.02.002.x

yöneticilerin maliyetlerin ya da işgücünün iyileştirilmesi arasında tercih yapmaları gerekmektedir.

\section{KAYNAKÇA}

Acar, M. F., \& Şevkli, M. (2013). Sınav çizelgelemesi için matematiksel model yaklaşımı. Verimlilik Dergisi, 2013(1), pp.75-86.

Aksu, O. R. (2018). Gözetmen Atama Problemine Yönelik Karşılaştırmalı Bir Matematiksel Optimizasyon ve Genetik Algoritma Yaklaşımı: Bir Üniversite Uygulaması. (Yayımlanmamış yüksek lisans tezi). İstanbul Yıldız Teknik Üniversitesi Fen Bilimleri Enstitüsü, İstanbul.

Altıntaş, C. (2011). Sezgisel Algoritmalarla Sınav Çizelgeleme Problemi Çözümü. (Yayımlanmamış yüksek doktora tezi). SDÜ Fen Bilimleri Enstitüsü, Isparta.

Altunay, H., \& Tamer, E. R. E. N. (2016). Ders Programı Çizelgeleme Problemi için 0-1 Tamsayılı Programlama Modeli ve Bir Örnek Uygulama. Uludă̆ University Journal of The Faculty of Engineering, 21(2), pp. 473-488.

Aslan, E., Şimşek, T., \& Karkacier, A. (2017). A Binary Integer Programming Model for Exam Scheduling Problem with Several Departments. Bilgi Ekonomisi ve Yönetimi Dergisi, 12(2), pp.169-175.

Aygün, S., and Akçay, M. 2015. "Matlab Paralel Hesaplama Aracı İle A* Algoritmasının Rota Planlama İçin Analizi". Genç Mühendisler Sempozyumu. İstanbul.

Ayob, M., Hamdan, A. R., Abdullah, S., Othman, Z., Nazri, M. Z. A., Abd Razak, K., ... \& Sabar, N. R. (2011). Intelligent Examination Timetabling Software. Procedia-Social and Behavioral Sciences, 18, pp.600-608.

Bergmann, L. K., Fischer, K., \& Zurheide, S. (2014). A Linear Mixed-İnteger Model for Realistic Examination Timetabling Problems. In Proceedings of the 10th International Conference on the Practice and Theory of Automated Timetabling. pp.82-101.

Blanks, L., Frakes, E., Hinnant, K., Samuel, S., \& Dulin, J. (2020). An Optimization Approach to the MakeUp Final Exam Scheduling Problem with Unique Constraints.

Bulut F., and Ince İ.F. 2018. “Tam Sayı Programlamada Açgözlü ve Sezgisel Aramalar ile 0/1 Sırt Çantası Problemine Yeni Bir Bakış", Karaelmas Fen ve Mühendislik Dergisi (8:1), pp.89-98.

Ceylan, Z., Yüksel, A., Yıldız, A., \& Şimşak, B. Sınav Çizelgeleme Problemi için Hedef Programlama Yaklaşımı ve Bir Uygulama. Erzincan Üniversitesi Fen Bilimleri Enstitüsü Dergisi, 12(2), pp.942956.

Çoruhlu, A. (2007). Sinav personel çizelgeleme modeli. (Yayınlanmamış yüksek lisans tezi). Gazi Üniversitesi Fen Bilimleri Enstitüsü. Ankara. 
Ibrahim, R., Amin, A. A. B., \& Saringat, M. Z. (2020). The Z Specification for Exam Scheduling System (ESS) thru Genetic Algorithm. In 2020 International Conference on Computing and Information Technology (ICCIT-1441) (pp. 1-5).

Inam, R., 2009. " $A^{*}$ Algorithm for Multicore Graphics Processors", Chalmers University of Technology, Master Thesis, Göteborg.

Kalaycı, C. B. (2008). Öğrenci başarısına odaklı sınav çizelgeleme modeli ve yazılım uygulaması. (Yayınlanmamış yüksek lisans tezi). Pamukkale Üniversitesi Fen Bilimleri Enstitüsü, Denizli.

Köçken, H. G., Özdemir, R., \& Ahlatcioglu, M. (2014). Üniversite Ders Zaman Çizelgeleme Problemi için İkili Tamsayili Bir Model ve Bir Uygulama/A Binary Integer Programming Model for University Course Timetabling Problem and a Case Study. Istanbul Üniversitesi İşletme Fakültesi Dergisi, 43(1), pp. 28.

Leite, N., Fernandes, C. M., Melicio, F., \& Rosa, A. C. (2018). A Cellular Memetic Algorithm for the Examination Timetabling Problem. Computers \& Operations Research, 94, pp.118-138.

Liu, Q., Li, X., Gao, L., \& Li, Y. (2020). A Modified Genetic Algorithm with New Encoding and Decoding Methods for Integrated Process Planning and Scheduling Problem. IEEE Transactions on Cybernetics.

Matçı, D. K. (2014). Sinav Görevli Atama Problemine Bir Çözüm Önerisi: Anadolu Üniversitesi Uygulaması. (Yayınlanmamış yüksek lisans tezi) Anadolu Üniversitesi Fen Bilimleri Enstitüsü, Eskişehir.

Muklason, A., Parkes, A. J., Özcan, E., McCollum, B., \& McMullan, P. (2017). Fairness in Examination Timetabling: Student Preferences and Extended Formulations. Applied Soft Computing, 55, pp.302-318.

Özçalıcı, M. (2017). Sınavlara Gözetmen Atama Probleminin Çözümü İçin Takas Bazlı Bir Algoritma Önerisi. Gazi Üniversitesi İktisadi ve İdari Bilimler Fakultesi Dergisi, 19(2), pp.492.

Seyfi, G. (2018). Metasezgisel Algoritmalar Kullanılarak Sınav Çizelgeleme. (Yayınlanmamış doktora tezi). Selçuk Üniversitesi Fen Bilimleri Enstitüsü, Konya.

Sun, Y., Raghavan, U. N., Vaze, V., Hall, C. S., Doyle, P., Richard, S. S., \& Wald, C. (2021). Stochastic programming for outpatient scheduling with flexible inpatient exam accommodation. Health Care Management Science, 1-22.

Temur, B. (2006). Investigating the Usability of Integer Programming for The Scheduling Process in an Educational Institute. (Yayınlanmamış yüksek lisans tezi). Marmara Üniversitesi Fen Bilimleri Enstitüsü. İstanbul.

Uçar, U., İşleyen, S., \& Demir, Y. (2015). Üniversite Ders Çizelgeleme Probleminin Bulanık Ahp ve Çok Amaçli Karışık Tam Sayılı Matematiksel Modelle Çözümü. Gazi Üniversitesi Fen Bilimleri Dergisi Part C: Tasarm ve Teknoloji, 3(3), pp.513-523.

Varlı, E., Ergişi, B., \& Eren, T. (2017). Nurse Scheduling Problem with Special Constraints: Goal Programming Approach. Erciyes Univ. Fac. Econ. Adm. Sci. J, pp.189-206. 


\section{AJIT-e Bilişim Teknolojileri Online Dergisi

2021 Spring/Bahar - Cilt/Vol: 12 - Sayı/Issue: 45

doi) 10.5824/ajite.2021.02.002.x

Yu, Z. (2020). A new approach to examination scheduling with allowable constraints for post-secondary institutions using GRA+. (Doctoral dissertation). Laurentian University of Sudbury.

Zhu, H., Yu, Z., \& Gningue, Y. (2020, October). Solving the Exam Scheduling Problem with GRA+. In 2020 IEEE International Conference on Systems, Man, and Cybernetics (SMC) (pp. 1485-1490). IEEE.

Ziegler, J., Werling, M., and Schroder, J. 2008. "Navigating Car-Like Robots in Unstructured Environments Using an Obstacle Sensitive Cost Function", IEEE Intelligent Vehicles Symposium, IEEE, pp. 787-791. 